\title{
The Impact of Online Game Addiction on Adolescent Mental Health: A Systematic Review and Meta-analysis
}

\author{
Eni Purwaningsih ${ }^{1}$, Ira Nurmala ${ }^{2 *}$ \\ ${ }^{1}$ Department of Health Promotion and Behavioral Sciences, Master Program of Public Health Sciences, Faculty of Public \\ Health, Universitas Airlangga, Surabaya, Indonesia; ${ }^{2}$ Department of Health Promotion and Behavioral Sciences, Faculty of \\ Public Health, Universitas Airlangga, Surabaya, Indonesia
}

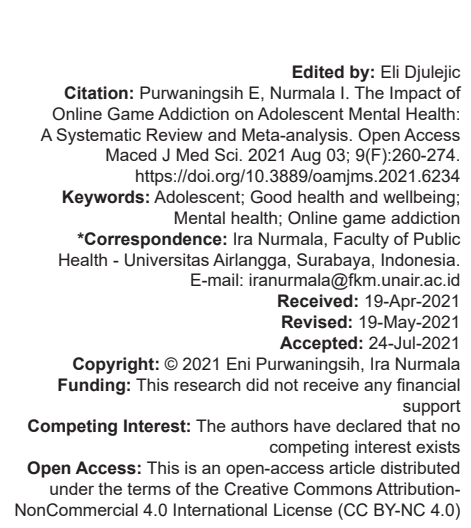

\section{Background}

Digital technology is currently advancing rapidly, making it easier for everyone to connect and share the same interests without any obstacles across geographic and temporal boundaries, convenient, flexible to reach, and affordable in developed countries; from these many advantages, there are also concerns among researchers related to the use of digital technology exaggerated [1]. One of the digital technologies that are currently in existence is online games. Online game games are currently booming among adolescent worldwide, even tournaments/competitions are held in playing them, which are integrated by the players' social networks. Internet addiction (IA) is currently considered a global problem with possible implications for mental health [2], [3].

The way people interact with technology is constantly changing. New behaviors have improved, social and recreational activities have changed, and new psychological problems have arisen. In the late 1990s, concerns about addictive internet use were discussed, and, since then, the concept has been widely studied and debated. Although it has been treated form different angels and researchers have used additional terms, "internet addiction" has become one of the most commonly used terms, along with "internet use is problematic" [4]. As the social problem of online gaming addiction has become widespread, online gaming has become viewed negatively such as gambling or alcohol addiction [5]. With the rapid surge in the population of internet users, IA has become an increasing mental health problem worldwide, raising public concern [2]. Healthily using the internet can be understood as achieving the desired goal in an appropriate time frame without experiencing any intellectual or behavioral discomfort [6]. IA is described as an individual's inability to control their use of the internet, which causes disruption and disruption in fulfilling work, social, and personal commitments and appears to have similarities with the category other aspects of behavior and substance use [6].

Since their commercial introduction in the 1970s, video games have become an integral part of modern leisure and entertainment. In particular, internet video 
games, particularly massively multiplayer online (MMO) games, have gained increasing research attention based on a compelling combination of functionality, socialization and development of play have many positive benefits and may improve endurance, spatial visualization, problem solving, communication skills, as well as educational and therapeutic benefits. However, the harmful effects of excessive gambling in a small group of individuals have also been demonstrated experimentally. This can include increased aggressive behavior and preoccupation, increased impulsivity and a tendency to play addictive games. Stavropoulos research investigating the adverse effects of gaming has led to developing and introducing diagnostic terminologies such as internet gaming disorder (IGD) and IA [7].

According to Nie et al., 2002 [9], about "bad internet" versus "good internet" is the current debate by reviewing the influence of internet use on social skills. The essence of socializing is personal interaction (face to face) and friendliness. On the one hand, the internet leads to more and better social relations by creating another medium of communication to friends and family and seeking new relationships without geographical, cultural, and time boundaries. However, on the other hand, it is predicted that internet use can be socially isolating because time in using the internet often sacrifices social activities and face-to-face interpersonal interactions [8].

Tateno et al. 2019, in his research, found that the trend of men preferring games in their internet usage. At the same time, women use the internet mainly for social networking through smartphones, and the average SAS-SV score (the Smartphone Addiction Scale [SAS]-Short Version) higher in women. According to the primary purpose of internet use, a two-group comparison between gamers and social media users shows that gamers use the internet longer and have significantly higher average the internet addiction test (IAT) and $\mathrm{HQ}-25$ scores [9].

During adolescence, new developmental tasks can pose significant challenges and psychological stress to the adolescent. In addition to practical problem-solving strategies, dysfunctional stress management strategies are often used to address these developmental tasks while also dealing with the struggle for freedom (from parental restraints, for example) or self-discovery. Given the pervasive pattern of problematic behaviors associated with adolescent digital media use, it seems quite appropriate to test whether there is an empirical relationship [10]. Addressing the issue of online gaming and the issue of mental health consequences children and adolescents playing online games is important given the usual trajectory of neurodevelopment; adolescence is characterized by increased maturation of the limbic system, which makes adolescents more likely to engage in addictive behavior than adults [11]. Therefore, this study set out to systematically examine the impact of online game addiction behavior on adolescent mental health.
This systematic review research and metaanalysis raised the theme of the impact of online game addiction on adolescent mental health. The independent variables analyzed were online game addiction. Research that discusses data on online game addiction is considered important because of its rarity. The dependent variable analyzed is adolescent mental health. The number of relevant research published and accessible is still small and also has data access problems [12]. Most of the statistical results reported are in percentage, correlation or only significant ( $p$-value), where the study does not control for confounding factors (confounding factors).

Confounding factors affect the relationship or effect of exposure to the occurrence of the disease estimated by the study that is not the same as the relationship or effect that actually occurs in the target population, so that the outcome invalid studies [12]. This systematic study and meta-analysis uses studies that control the confounding factors that can be seen from the research inclusion requirements, namely, using multivariate analysis and the statistical results reported are adjusted odd ratio.

The combined estimate of the impact of online game addiction on adolescent mental health was processed using the RevMan 5.3 application with the generic inverse-variance method [13], [14]. This method is used to analyze data in the form of rate, time to event (time-to-event), hazard ratio (hazard ratio), ordinal scale, adjusted estimate (adjusted estimate), and difference of mean or ratio of mean.

The results of systematic studies and metaanalyses are presented in the form of forest plots and funnel plots. The forest plot shows visually the magnitude of variation (heterogeneity). The funnel plot shows the relationship between the study's effect size and the sample size of the various studies studied, which can be measured in different ways [12].

Various studies have been conducted to reduce the risk and impact of online game addiction on adolescent mental health. And also most of the existing research is based on schools and adolescents, so this study looks at the impact of online game addiction on adolescent mental health, but the results of the research still do not show consistent results. Further analysis is needed to get a convincing conclusion regarding the impact of online game addiction on adolescent mental health using a systematic review and meta-analysis.

\section{Methods}

\section{Strategies for finding relevant studies}

Articles published in English are searched on PubMed, Science direct, Sage and Scopus. Relevant 
literature was searched from February to March 2021. Publication time is limited to 2011-2021. Search terms were "online game addiction," "mental health," and "adolescent." The technique used for keywords uses Boolean operators and truncation to broaden and narrow the search. Results from four databases yielded 81 articles. As the initial layer, the title and abstract are read and filtered independently by the main author and checked by the second author. Any articles that are not relevant to the topic of online game addiction are immediately removed. Inclusion criteria include journals in English published in the past ten years, data collected both qualitatively and quantitatively or a combination of both, focus of study on adolescents 13-18 years, and the full text is available.

After being collected, 81 articles were carefully examined for relevance so that 20 articles were finally selected to be included in the scoping review of this journal. The last collection of articles was tabulated, and the main findings of each article were mapped to share the latest knowledge about online gaming addiction. The following data were taken from each article: Author, year and place of study, study design, and the primary purpose of the study. Guided by research questions, what are the characteristics of online game addiction symptoms and their implications for adolescents' mental and physical health. The articles are then compared and grouped into broad categories. Eighty-one articles were carefully examined for relevance so that 20 articles were finally selected to be included in the scope review of this journal. The last collection of articles was tabulated, and the main findings of each article were mapped to share the latest knowledge about online gaming addiction. The following data were taken from each article: Author, year and place of study, study design, and the primary purpose of the study. Guided by research questions, what are the characteristics of online game addiction symptoms and their implications for adolescents' mental and physical health. The articles are then compared and grouped into broad categories. Eighty-one articles were carefully examined for relevance so that 20 articles were finally selected to be included in the scope review of this journal. The last collection of articles was tabulated, and the main findings of each article were mapped to share the latest knowledge about online gaming addiction. The following data were taken from each article: Author, year and place of study, study design, and the main purpose of the study. Guided by research questions, what are the characteristics of online game addiction symptoms and their implications for adolescents' mental and physical health. The articles are then compared and grouped into broad categories. The last collection of articles was tabulated, and the main findings of each article were mapped to share the latest knowledge about online gaming addiction. The following data were taken from each article: Author, year and place of study, study design, and the main purpose of the study. Guided by research questions, what are the characteristics of online game addiction symptoms and their implications for adolescents' mental and physical health. The articles are then compared and grouped into broad categories. The last collection of articles was tabulated, and the main findings of each article were mapped to share the latest knowledge about online gaming addiction. The following data were taken from each article: Author, year and place of study, study design, and the main purpose of the study. Guided by research questions, what are the characteristics of online game addiction symptoms, and their implications for the mental and physical health of adolescents. The articles are then compared and grouped into broad categories.

\section{Results}

Results that the results obtained from 20 articles analyzed showed that almost all articles discussed and showed results about the impact of online game addiction on adolescent mental health. This impact does not only occur in adolescents, but also in adults. The results of the analysis also found that family relationships play an important role and maybe one of the risk/protective factors associated with the IGD, which has been explored as perceived family disharmony, parental inconsistency, family dysfunction, poverty, and family relationship problems [15].

Review several articles also explain the risk factors and symptoms of the emergency department. They also explain the prevention and treatment of the emergency department and policy recommendations for handling the emergency department in the field of public health. Based on the 20 articles analyzed (Table 1 and 2), seven studies (35\%) were studies in 2019.

Table 1: General characteristics of selected studies $(n=20)$

\begin{tabular}{lll}
\hline Category & $\mathrm{n}$ & $\%$ \\
\hline Publish year & & \\
2011 & - & - \\
2012 & - & - \\
2013 & - & - \\
2014 & 1 & 5 \\
2015 & 1 & 5 \\
2016 & - & 10 \\
2017 & 2 & 10 \\
2018 & 2 & 35 \\
2019 & 7 & 30 \\
2020 & 6 & 5 \\
2021 & 1 & $100 \%$ \\
Total & 20 Articles \\
Research location (country) & & \\
Italy & 1 & 6.7 \\
Spanish & 2 & 13.3 \\
India & 1 & 6.7 \\
Germany & 2 & 13.3 \\
Korea & 2 & 13.3 \\
Hong Kong & 1 & 6.7 \\
Taiwan & 2 & 13.3 \\
Finland & 1 & 6.7 \\
Saudi Arabia & 1 & 6.7 \\
Belgium & 1 & 6.7 \\
United Kingdom & 2 & 13.3 \\
China & 1 & 6.7 \\
Turkey & 1 & 6.7 \\
Spain & 1 & 6.7 \\
Germany \& Austria & 1 & 6.7 \\
Total & 20 Articles & $100 \%$ \\
\hline & & \\
\hline
\end{tabular}




\section{Type of game online addiction}

\section{Problematic internet use (PIU)}

There are many terms and concepts regarding PIU in the existing literature. When first introduced by Young, "Internet Addiction" was the most common term, as the diagnostic criteria proposed were based on the measures applied to the disease. However, in the absence of a prolonged formal diagnosis, the study by Lai and Kwan's 2017 switched to the use of other terms or definitions such as "problematic internet use" (PIU) and "compulsive internet use" to avoid confusion with psychiatric disorders. Identified in Study I, there is an indirect negative effect of family income on PIU through better relationships with teachers, leading to greater use of the internet in learning and therefore better learning outcomes. The early stages of mediation are not a surprising finding, as the previous research has shown that students from older families tend to have better relationships with teachers and better interpersonal relationships in general, possibly due to more developed social and communication skills [16].

\section{IA}

IA can be defined as the inability to control one's internet use with negative consequences and long term for a considerable time [17]. However, there is no general consensus on the definition of IA. Research shows that addiction is actually linked to the use of certain online activities, meaning that each addiction is characterized by a certain behavioral behavior according to this viewpoint considers certain common elements in the spectrum of addiction must be recognized as impulsive personality and addictive personality [17].

\section{IGD}

The definition of game addiction refers to the excessive and compulsive use of video games resulting in social and emotional problems; despite these problems, and the player cannot control the use of video games [5]. Increase in the time and frequency of online games can lead to negative consequences, the most consequences discussed consequences in the scientific literature being IGD and aggressive behavior in boys playing certain actions. IGD was recently introduced in the Nosology textbook as an addictive behavior disorder. The International Classification of Diseases $11^{\text {th }}$ edition (ICD-11) considers IGD among addictions beyond the fact that addictive behavior involves the use of psychostimulants and is characterized primarily by greed. Repeated and continuous engagement in online games results in clinically severe pain, with a broad spectrum of psychological problems including depression, anxiety, social phobia, poor school performance (achievement), and sleep deprivation[18], [19], [20].
The American Psychiatric Association (APA) definition of IGD in the Diagnostic and Statistical Manual of Mental Disorders (DSM-5) $5^{\text {th }}$ Edition follows the criteria for substance abuse and problem gambling.

1. Having fun with gambling

2. Withdrawal symptoms from not playing the game

3. Tolerance, need to spend more time gambling

4. Unable to stop or control gambling

5. Loss of interest in recreational activities other than games

6. Continuing to play despite psychosocial problems

7. Lying and deceiving others about games numbers

8. Using video games to escape negative moods or life problems real life

9. Loss or risk of losing meaningful relationship, career, or educational opportunity as a result of gambling.

In the latest edition of the ICD-11, online gaming behavior is included as a diagnosis including addiction disorders. In ICD-11 gaming disorder is characterized by persistent or repetitive patterns of digital gaming or video game behavior that may manifest online or offline as.

1. Impaired control over game (e.g., onset, frequency, intensity, stopping duration, and context)

2. Increase the priority given to playing games in the sense that games take precedence over daily interests and activities over other life

3. Continuation or escalation of the game despite negative consequences [21].

The above behavior patterns are quite severe enough to cause significant damage in the areas of personal, family, social, educational, work, or other essential functions [22].

According to research by Fernández-Villa et al., 2015 [23], found a significant relationship between several health problems (migraine, back pain, overweight or obesity, and insufficient rest), psychological aspects (risk of eating disorders, risk of mental disorders, and depression), family problems and discrimination, without any association with substance use (alcohol, marijuana, or tobacco) was found. However, for some players, overuse fosters dependence, leading to negative psychosocial and health consequences konsekuensi [24].

A literature review conducted by Mihara and Higuchi found that the prevalence of IGD ranges from $0.7 \%$ to $27.5 \%$, depending on the sample. The rate is higher for men than for women and tends to be higher for young people. The prevalence rates found in different studies also vary slightly from country to country. Factors associated with IGD are gambling characteristics, demographic variables, family socioeconomic level, and academic performance [25]. 
IA/addiction (such as online gaming) has detrimental effects on the lives of adolescents, such as reduced academic performance, physical and mental health and adolescent relationships. Therefore, monitoring internet usage behavior such as online gaming among adolescents is necessary for early detection of IA. IGD is associated with well-documented psychological distress. For example, the IGD has been associated with depression, anxiety, obsessivecompulsive behavior with inattention, hyperactivity, low self-esteem, loneliness, and social phobia [26], [27]. A study in India stated that depression is a major comorbid disorder of IA, self-esteem is an individual's attitude toward himself which can be positive or negative and is understood as one of the core components of depression. Thus, individuals with irrational cognitive assumptions about themselves are likely to have lower self-esteem and tend to engage in addictive behaviors that help them temporarily break away from their cognitive premises about themselves [5].

In a study conducted by Niko Mannikko, Joel Billiex and Maria Kaariainen Oulu with the topic "Problematic digital gaming behavior and its relation to the psychological, social and physical health of Finnish adolescents and young adults" the results showed a significant relationship between fatigue, depression, anxiety, trouble sleeping, and problems when focusing on problem gaming scores (online game addiction) [28].

A study conducted by Han et al., 2020, examined the relationship between the genre of online gambling and IGD risk of erectile dysfunction in schoolgoing adolescents. The research subjects are only users of online games and the general characteristics show that the percentage of boys $(67.7 \%)$ is higher than that of girls. Overall, the rate of gambling use by gender tends to be higher for men than for women. A 2015 survey of gaming usage rates in the general population found that among all online gaming users, the percentage of men was $66.3 \%$, a trend consistent with the current survey [16]. Meanwhile, the prevalence of IGD in high-risk individuals was $10.1 \%$ in this study, similar to the $11.5 \%$ and $9.0 \%$ reported by the previous studies of IGD prevalence [25], [26]. However, due to the differences in the tools is used in each study [29].

Research conducted by Alshehriand Mohamed, 2019 in Saudi Arabia shows that playing video games negatively affects men's health, social relationships, and physical activity. The most negative endpoint was the correlation between video games and physical activity $(r=0.49)$, followed by social relationships $(r=0.42)$ and BMI $(r=0.31)$. The lowest results were in health $(r=0.20)$. More empirical investigations are needed to explore the deeper effects of video games on different groups in Saudi society, including the general population, employees, and school types, and different students [30].

In a study conducted by Deleuze et al., 2017 with participants who were players over 18 attending universities in Belgium, questioned the validity of the IGD DSM-5 Criteria using the original method of multiple classifiers. This study requires further development and refinement of the diagnostic criteria used to define the IGD on a broader level. In particular, Deleuze et al. believe that establishing a specific list of diagnostic criteria for IGD also requires focusing on the unique psychological and behavioral characteristics associated with the disease [31], rather than simply exploiting the similarities with substance abuse disorders. In addition, the diagnostic criteria must make it possible to separate the increased healthy association with the pathology to limit the risk of pathologically normal behavior. Regarding the latter, the latest guidelines provided by the World Health Organization (WHO) (2017) in the beta version of the $11^{\text {th }}$ revision of the ICD appear to be an improvement, as they do not include peripheral criteria and take explicitly take into account the functional impairment as a mandatory diagnostic criterion.

A study in Korea on the gap between selfreport and clinical diagnosis of IGD in adolescents conducted by Jeong et al. 2018 concluded that the difference in diagnosis was IGD between selfreport and clinical diagnosis reveals limits of selfmeasurement. Various strategies are needed to fill the gap in self-assessment methodology for IGD assessment. It is difficult to accurately assess adolescents risk behaviors using self-reported questionnaires. Adolescents at risk for various disorders may not want to reveal specific facts about themselves, and they may deliberately conceal risky behavior that is not socially desirable. The effects of social desirability can threaten the validity of the results because the responses are systematically biased by definition respondent, who wanted to present themselves in a favorable condition, may or may not consciously adjust their responses to make their behavior less deviant and more social as the social desire bias causes players to underreport their playing time to online games can also signal a lack of time to play games for other reasons (e.g., losing track of time while immersed in an activity). The way data are collected can influence the degree of social desire bias may or may not consciously adjust their responses to make their behavior less deviant and the more social postulate that social desire bias causes gamers to underreport their playing time. Individuals who play online games may also underreport gaming time for other reasons (e.g., lost track of time while immersed in an activity). The way data are collected can affect the degree of social desirability bias [32].

According to Volmer et al., 2014 research results on adolescents in Turkey concluded that the types of adolescents who play online games at night may be more prone to computer game addiction than the types of adolescents who play online games in the morning [33]. 


\section{Risk factor of online game addiction}

\section{User motivation to play online games}

The IGD risk factor is the user's motivation for play online games. Higher risk when the reason is to relieve stress, and or avoid reality. This motive is associated with specific games such as first-person shooters, which play for skill and control, but a third of online multiplayer games play (MMORPG) that players play to relieve stress and deal with boring daily activities. Wanting to escape reality is a necessary motivation when faced with the problem of using online games. However, there are serious gaps in research on the effects of online gaming, as some studies have taken gaming platforms into account. Most studies on the health effects of online gaming have focused on the effects of online gaming on personal computers, specifically the MMO battle arena games MMORIX 240 (MOBAS). However, CVG smartphones like Candy Crush Saga can be addictive because they can be played anywhere and anytime for entertainment, connecting with friends, enjoying the feeling of victory while relaxing or killing time, and the use of these games is lonely and lacks of self-control [18].

\section{Types of online games}

At present, the most popular video games are MMO role-playing games (MMORPGs), flash games, and online slots. MMORPGs are online roleplaying game that mainly focuses on fantasy stories or storyline conflicts. It is about creating a digital avatar, an identity and an appearance, and a virtual world where the players interact through their avatar [3]. Yee's three motivators in Goh et al., 2019 to play MMORPG (Directing, Social Interaction, and Inclusion) were tested as a mediator between playtime and psychological well-being. Research found that an increase in gaming was associated with lower psychological well-being, especially when players had a greater incentive to indulge and avoid, leading to a negative relationship between alcohol use and addiction, using games to escape real-life problems and poor mental health [34].

\section{IGD and family relationship}

Emerging evidence suggests that family relationships play an important role and maybe one of the risk/protective factors associated with the IGD that has been explored as perceived family disharmony, parental inconsistency, family dysfunction, poverty, and family relationship problems [15].

From the study on "Multi-dimensional correlates of IA symptoms in adolescents with attention-deficit/hyperactivity disorder" conducted by Chou et al. in some adolescents (11-18 years old) diagnosed with ADHD (attention-deficit/hyperactivity disorder symptoms) in Taiwan results show that low satisfaction with family relationships was the most important predicting of IA severe, followed by the use of instant messaging (messenger), watching movies, the fun-seeking system (behavioral approach system [BAS]), and the Behavioral Inhibition System that scored high. Meanwhile, poor father's work, poor BAS drive, and online gaming were significantly associated with severe IA symptoms [35], [36]. While, ADHD symptoms include inattention, hyperactivity, impulsivity, and oppositional symptoms of oppositional (aggressive) disorders [36], [37]. The previous studies explored these aspects in subjects with IGD and has led researchers to propose a classification of different types of players. Lee and collaborators identified three main types: Impulsive/aggressive gamers, emotionally vulnerable players, and socially conditioned players [2].

Jia et al., 2021 summarize internet overuse's dynamic findings and clarify how peer transmission occurs with Internet overuse behavior and peer attitudes toward internet overuse [38]. According to Choi et al. 2018 in his research showed the results that adolescents from dual-income families had a significant relationship with all factors of online game addiction and juvenile delinquency [4].

\section{Impact of the emergency room}

Hui et al. 2019 wrote that online gaming is a global concern, especially in China. According to the China Internet Network Information Center, the number of domestic online game players has increased from 336 million to 422 million in the past 5 years, achieving a growth rate of $25 \%$. Although recognized for recreational function of online gaming, excessive and prolonged online gaming can have adverse effects, including poor academic performance, poor health, and feelings of loneliness, as well as a lack of real relationships. More seriously and specifically, online gamers may eventually develop an IGD, which has been labeled as a condition for further investigation in the DSM-5 and recognized as a new mental health condition in the $11^{\text {th }}$ WHO as a new mental health problem, edition of the ICD-11. As high schools, technical high schools, technical schools, and college students make up the majority $(55 \%)$ of Chinese online game players, further research attention should be devoted to reduce the risk of IGD on campus [39].

Kumcagiz's research in Turkey showed the results of a one-way ANOVA test that students whose fathers had a low level of education were more likely to have higher IA scores than students whose fathers had a high level of education. The results of Pearson's product-moment correlation coefficient showed that students' IA scores were negatively correlated with age, mean grades, maternal care, maternal overprotection, paternal overprotection, and paternal overprotection. However, the stepwise regression analysis results showed that the most important predictors of IA 
scores were maternal overprotection and paternal overprotection; the results also show that age, mean grades, maternal care, and paternal care [40].

Research by Lin et al., 2014 [41] on adolescents in Taiwan showed that adolescents with IA were more likely to have suicidal ideation and attempts. Given that IA is associated with depression, low-income family support, and low self-esteem, these factors increase the risk of suicide.

\section{Treatment of online game addiction} manual treatment

\section{Cognitive behavioral therapy (CBT)-based}

In 2013, the APA included IGD in the fifth edition of the DSM-5 [43] in the attachment to DSM 5, it is added that the emergency department is included as a condition that requires further research before being classified as an official mental disorder [31]. The WHO in 2019 determined that the IGD is one of the mental health disorders [43]. According to the two organizations, IGD disorder refers to a minimum period of out-of-control behavior. The priority is internet games such as online games and neglecting other activities such as social activities, work, study, recreation, and other important activities that cause adverse effects. In adolescents, it can be in the form of decreased achievement, lazy to study and others. Other technology-mediated behaviors are thought to be linked to adverse mental health effects, including the use of social media, smartphones, and online pornography [1].

According to Wolfling et al., 2019, the long-term treatment for internet and computer game addiction is manual treatment based on CBT for 15 weeks for IA. This model is based on the integrated process model of internet addiction (InPRIA-model) which conceptualizes IA due to a dynamic interaction of individual factors, online activity features, dysfunctional coping strategies, and addiction-specific cognitive biases. Treatment phase overview 15-minute group sessions (100 min) and eight individual sessions (60 min) interspersed in the program to promote treatment motivation and provide crisis intervention. A clinical psychologist carries out therapy or physical doctor who has completed psychotherapy training and is undergoing CBT training continued [43].

Many terms have been used to describe IGD in the literature including internet game addiction, online game addiction, computer game addiction, and pathological game. Following the APA category, the term IGD is used in the current article. The IGD as a newly proposed mental disorder was not recognized by primary care providers (PCPs) in its infancy. However, the IGD cannot be ignored and is a severe health problem, likely to be underreported and underestimated in clinical practice. PCPs from various disciplines, including family physicians, mental health counselors, and community nurses play an important role in the early recognition and timely provision of IGD care [44].

IGD screening tools-TIG TOC and instruments problematic internet use questionnaire (PIQ)

In today's modern era cannot be separated from the internet and online games. However, it is important to wisely control their use and distinguish between problematic and non-problematic games to play, especially for adolescent. There needs to be a screening tool that can determine clinically and identify game disorders for individuals who need professional help. When discussing characteristics related to online game addiction problems, one of the variables often mentioned is excessive use, namely, the amount of time spent playing online games. According to Sun et al., 2020 , the sensitivity and specificity of time spent playing online games do not adequately serve as a screening tool to assess the risk of online gaming disorder. The greatest strength of the current study is that we evaluated the criteria-related validity of the TIGTOC using a methodology that met the Quality Assessment of Diagnostic Accuracy Studies tool - International quality standards for diagnostic studies. To do so, a blind mental health specialist conducted a one-onone diagnostic interview with all subjects to establish an IGD diagnosis based on the DSM-5 criteria; this diagnosis is used as the external gold standard. In this study, the empirical cutoff score on the TIGTOC was sufficient to distinguish between non-problematic and problematic use of online games. In addition, Sun Je Jo found that TIG-TOC scores were positively associated with weekly time spent playing online games, measures of IA obtained through the IAT, ADHD symptoms, and depressive symptoms; TIGTOC is a reliable tool with a high Cronbach alpha. However, despite the strength that the gold standard for ED diagnosis is determined through such a rigorous process [11].

According to Rodda et al. [46], although evidence suggests that most people self-medicate their IA, little is known about the type, or efficacy, of the methods they employ. Technology addiction may contribute to poor academic performance and depression. This requires studies on a larger scale, with interventions for judicious use of gadgets [46].

A study in Japan provided evidence of the Japanese version of the PIQ. In this study, the shortened form of the PIUQ is the shortest continuous scale available to assess PIU in Japan. Due to its concise and convenient format, this newly translated measure will facilitate investigation of PIU in the Japanese population and provide a screening tool and allow cross-cultural comparisons. It will also be useful for assessment in the evaluation, prevention, and treatment of PIU in public health [47]. 


\section{Policy recommendations}

\section{Approach to stakeholders}

To prevent the emergence of problematic use of technology and reduce harm, a multi-stakeholder approaches such as researchers, doctors, regulators, government agencies, community organizations, and industry is used. Relevant government agencies and industries that benefit from the implementation of online games such as online gambling, have a duty to maintain, social responsibility, and moral obligations to avoid practices that can increase losses due to online gambling games and take active steps to prevent and reduce the hazards associated with them. Likewise, user protection and prevention of harm are clinical and moral obligations for professionals who work in online games and activities that can potentially harm users. There is a need for user information and behavioral prevention approaches adopted in different countries, focusing on skillbuilding, protecting users, limiting any harm, and simultaneously assessing risky behavior. Community organizations and governments should engage in education and awareness campaigns to help technology users develop the skills and behaviors critical of the content they consume and develop safe practices such as boundary setting. There is a need for user information and behavioral prevention approaches adopted in different countries, focusing on skill-building, protecting users, limiting any harm, and simultaneously assessing risky behavior. Community organizations and governments should engage in education and awareness campaigns to help technology users develop the skills and behaviors to be critical of the content they consume and develop safe practices such as boundary setting. There is a need for user information and behavioral prevention approaches adopted in different countries, focusing on skill-building, protecting users, limiting any harm, and simultaneously assessing risky behavior. Community organizations and governments should engage in education and awareness campaigns to help technology users develop the skills and behaviors to be critical of the content they consume and develop safe practices such as boundary setting.

\section{Product design and consumer protection tools}

Tocreate norms around technologyuse behavior and an understanding of the possible problematic use of technology, an international perspective is essential as the cultural context plays a major role. It is not enough to rely on individual behavior for the prevention of harm ranging from mild to severe, government organizations and regulators must also act to prevent products, the environment and marketing that may be too harmful for those most vulnerable to problems that will develop especially in young people and those with mental health problems. For online gaming, there needs to be establishing a framework for appropriate and non-conforming product design and requirements for consumer protection tools such as limiting in-game spending and time. Research is needed that informs the suitability of using certain digital technologies across user age groups and implementing relevant user protections. Implications for clinical practice include establishing dialogue among experts in the field, including physicians, social workers, educators, technology users, and other interested people. A good balance must be struck where everyday behaviors are not pathological and risky behaviors are identified and prevented from developing into problematic behaviors. A developmental perspective needs to be considered when young users and behavioral problems need to be contextualized according to the families involved in the treatment [1]. In addition, providing information and interventions appear to be a critical public health strategy for preventing and addressing problems in all settings [49].

\section{Promoting education on offline and online} health behavior in adolescent populations

The second policy is aimed at all Internet users, especially those who appear to be at greater risk of developing addiction problems related to internet use. All the studies reviewed have highlighted the general aspects of promoting healthy internet use, particularly among adolescents and young adults, as some game genres are highly demanding regarding competition and social engagement (e.g., MMORPGs). Preventive measures that can be taken include:

1. To encourage alternative motivation, involvement in alternative entertainment behaviors (also those including internet use), new coping skills, cognitive and emotional skills, healthy attachment styles to reduce the risk of internet use-related problems and to reduce Internet use, if needed (e.g., through alerts and notifications) and to provide alternative relaxation options (e.g., reading, meeting people, and engaging in physical activity)

2. To detect the risk of experiencing comorbidities or other problems and address them with professional support and the support of significant others (e.g., caregivers in adolescents) and embrace a systemic approach

3. Suppose there is a problem with internet use. In that case, all Internet use-related addictions should be assessed simultaneously, as many of the studies reviewed were clinical studies on gaming addiction, which together with gambling in young adults appear to represent a worst-case scenario in this regard [48]. 


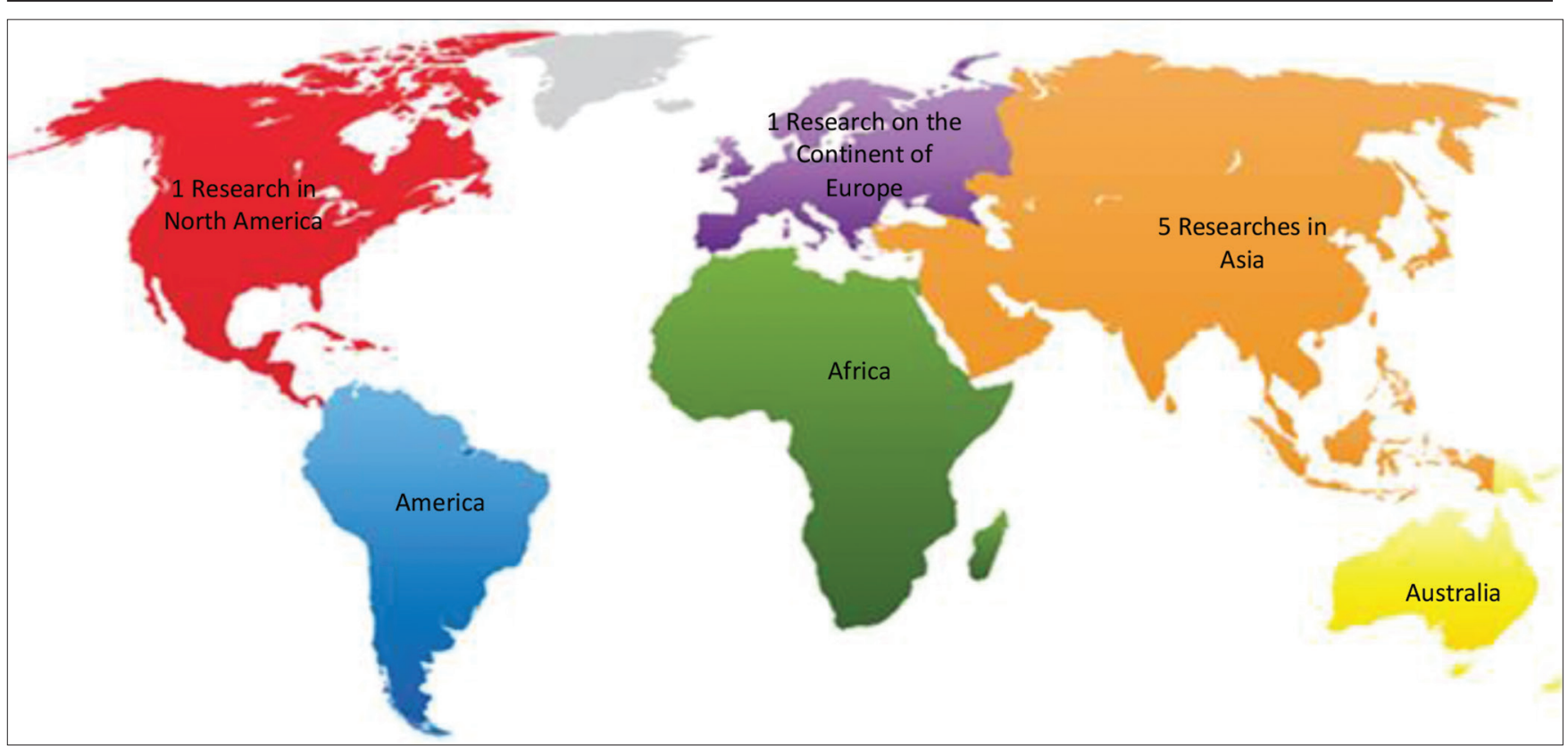

Figure 1: Research Area Map Wilayah

\section{Discussion}

Research studies around online game addiction and its relationship to adolescent mental health are still very limited. This systematic review study describes the above topics regarding the health effects of the IGD in detail starting from the type of IGD, IGD risk factors, and IGD treatment.

Figure 2 shows the areas where articles were published according to the inclusion criteria. The articles in this study come from three continents, namely, Asia, Europe, and North America.

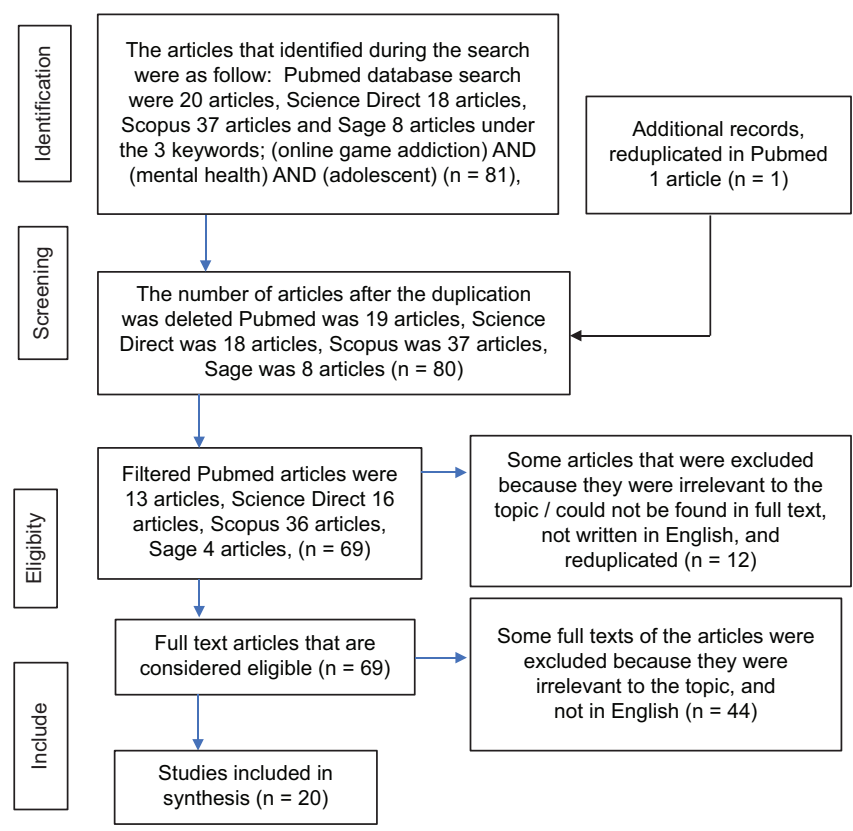

Figure 2: PRISMA flow chart diagram

In De Pascuale's research, the data showed a positive correlation between higher online game use and higher rates of depression $(r=0.501)$, anxiety $(r=0.361)$ and psychoticism $(r=0.431)$, and lower family and extra-family relationships $(r=0.383)$, and lower family and extra-family relationships $(r=0.383)$. In linear regression analysis, somatization $(p=0.002)$, depression $(p=0.001)$, and sleep disturbance ( $p=0.003$ ) were predictors of IGD diagnosis. IGD was significantly associated with mental health disorders. In line with the results of research by Beranuy et al., 2020, a positive and significant relationship was found between IGDS9-SF (Internet gaming disorder shortform scale), CERM (Mobile-related Experience), and OGD-Q (Online Gambling Disorder Questionnaire). Participants classified with the IGD had a poorer health-related quality of life. Almost all selected studies showed the same result, namely, the existence of a significant relationship between the behavior of the emergency room and the mental health of adolescents in particular.

Table 3 shows seven observational study articles on the impact of online game addiction on adolescent mental health. Five studies came from the Asian continent (three from Japan, one Korea, and one Taiwan), and the other two studies came from the North American continent and the European continent (Mexico and Spain). Suppose adolescent play online and offline games excessively without knowing the time. In that case, it can cause adolescent to neglect other activities, even to eat, to have a destructive impact on their nutritional status. According to psychologist Tara Adhisti de Thouars during the lightHOUSE Indonesia media gathering at Wyl's Kitchen di Jakarta on Friday 24 February 2017 inEvana Nisa'ul Ammar and Ira Nurmala 2020 eating disorders have a very serious impact, namely, death, eating disorders themselves are a health problem that contributes to high mortality rates in clinical cases of mental disorders. The existence of 


\begin{tabular}{lll}
\hline Author & Research design & Sample \\
\hline De Pasquale et al. & Quantitative & 566 young adults (324 boys/242 \\
(2020) & & girls; ages 18-35 years: $22.74 \pm$ \\
& 4.83 years) in Italy
\end{tabular}

Beranuy et al. (2020) Quantitative

$\begin{array}{ll}\text { Nitin et al. (2018) } & \text { a cross-sectional } \\ \text { study design }\end{array}$

1763 medical students aged

Wartberg and Quantitative

$\begin{array}{ll}\text { Jo et al. (2020) Cohort Study } & \begin{array}{l}2319 \text { teenage internet users in } \\ \text { Korea }\end{array}\end{array}$

Lai and Kwan (2017) Quantitative

Kindt et al. (2019) longitudinal, randomized controlled study

González-Bueso Quantitative et al. (2020)

Chou et al. (2014) Quantitative

$\begin{array}{lll}\text { Lin et al. (2021) } & \text { Cross Sectional } & \begin{array}{l}320 \text { adolescent and siblings } \\ \text { (Taiwan) }\end{array} \\ \begin{array}{l}\text { Männikkö et al. } \\ \text { (2015) }\end{array} & \text { Cross Sectional } & \begin{array}{l}293 \text { respondents aged 13-24 years } \\ \text { in Finland }\end{array}\end{array}$

Han et al. (2020) Cross-Sectional 1,532 high school students using

Alshehri et al. (2019) Cross-sectional survey study
535 Vocational Training students in Spain (mean age 18.35 years; SD $\pm 2.13 ; 78.5 \%$ male) who reported playing video games in the last 12 months $18-21$ years in three cities in India

633 adolescent

(median age: 15.79 years) in Germany

744 students from two Hong Kong secondary schools

418 students aged between 11 and 21 years $(M=15.10, S D=1.97)$, in Germany

A total of 287 adolescents diagnosed with ADHD and aged between 11 and 18 years in Taiwan online games in Seoul, Korea

Mobile Phone-Related

Experiences (CERM), Interne

Gaming Disorder Short Form

Scale (IGD9-SF), Online

Gambling Disorders Questionnair

(OGD-Q), and KIDSCREEN-27 with health-related quality of life Internet use behavior with Internet use behavior with
psychological stress, especially depression

problematic alcohol use, social media use, problematic Internet use and mental health

The Three-item-Online-Centered Gaming Disorder Test (TIGTOC) four-point Likert scale selected

from the Internet Gaming Induced Symptoms Screen

(I GUESS)

Adolescent problematic Internet use and family socio-economic variables

School-related factors such as absenteeism, school grades, procrastination, school-related social behaviors, and learning behaviors and IUD symptoms (Internet use disorder) Internet use variables (time spent online and playing games) and school-related psychological variables (procrastination, learning were assessed through a selfreport questionnaire Subject's Personality and Symptom Check List-90 itemsRevised, all State-Trait Anxiety Index scales, and DSM-5 IGD criteria

Internet addiction, family relationship satisfaction, instant messaging, watching movies, pleasure-seeking (BAS) Behavioral Inhibition System, SES, and online gaming behavio

Internet gaming disorder, psychological stress, and sleep problematic gaming behavior, psychological, social, and physica health symptoms

High risk of Internet gaming disorder and online game genres used by adolescent

194 respondents aged $17.23+1.52$ Behavior of playing electronic years in Saudi Arabia games with health, socia

Variable

Online game use, depression,

anxiety, psychoticism, family

relationships, sleep disorders,

Data collected by questionnaire

Internet Gaming Distraction Scale

Short Form (IGD9-SF); the APA

symptom checklist, based on

the DSM- 5 diagnostic criteria for

the ED; Revised Symptom-90

Checklist (SCL-90 R); and the

Social Adaptation Self-Evaluation Scale (SASS) problematic gaming, problematic consists of three items using a behavior, and social behavior)

Results

The data showed a positive correlation between higher onlin game use and higher rates of depression $(r=0.501)$, anxiety $(r=0.361)$ and psychoticism $(r=0.431)$, and lower family and extra-family relationships $(r=0.431)(0.383)$. In linear regression analysis, somatization $(p=0.002)$, depression $(p=0.001)$ and sleep disturbance $(p=0.003)$ were predictors of ED diagnosis. ED was significantly associated with mental health disorders

A positive and significant relationship was found between IGDS9-SF, CERM, and OGD-Q. Participants classified with the ED had a poorer health-related quality of life

Internet addiction is significantly and positively correlated with psychological distress in medical students in India

Correlation analysis showed a statistically significant positive bivariate relationship between the four respective behavioral patterns. Antisocial behavior is associated with all problematic behavior patterns. Meanwhile, emotional distress, self-esteem problems and hyperactivity/inattention were only associated with non-substancerelated problematic behavior patterns

TIGTOC scores were positively associated with time spent playing online games, depressive symptoms, attention-deficit/hyperactivity disorder symptoms, and addictive internet use

In particular, it was found that parental education and family income significantly moderated the relationship between the amount of Internet use and the

severity of PIU

This study shows the importance of school-related factors in the development of the IUD, especially psychological factors that play a role in the school environment.

Gaussian mixed model cluster analysis was used to classify subjects based on their personality. Two groups based on personality traits were detected: type I "high comorbid symptoms" (n $=24)$, and type II "low comorbid symptoms" ( $n=42)$. Type I includes higher scores on the traits of introverted, inhibited, doleful, unruly, strong, antagonistic, condescending and borderline tendencies, and lower scores on traits histrionic, egotistical and conformable. Type I scores higher on all 90-item Revised Symptom Check Lists, all State-Trait Anxiety Index scales, and the ED DSM-5 criteria The results showed that low satisfaction with family relationships was the strongest predictor of severe internet addiction symptoms, followed by instant messaging, watching movies, Behavioral Approach System pleasure-seeking, and high Behavioral Inhibition System scores. Meanwhile, SES (parental occupational socioeconomic status) low father's occupation, low BAS drive, and online gaming were also significantly associated with severe internet addiction

The pair effect of the IGDS-SF9 score on depression, anxiety, stress, and insomnia severity was significant in both adolescents. Problematic gaming behavior was associated with psychological and health problems, namely fatigue, sleep disturbances, depression and anxiety symptoms. Multiple linear regression showed that weekly play volume, depression and preference for online social interaction predicted an increase in problematic gaming symptoms This cross-sectional study found an association between online game genre and ED risk in adolescents who attend schoo

The results showed that playing electronic games negatively correlated with health, social relationships, and physical activity in relationships, and physical activity men. The most significantly negative was the correlation between in men electronic games and physical activity $(r=0.49)$, followed by social relations $(r=0.42)$ and BMI $(r=0.31)$. The lowest outcome was for health $(r=0.20)$ 
Table 2: (Continued)

\begin{tabular}{|c|c|c|c|c|}
\hline Author & Research design & Sample & Variable & Results \\
\hline Deleuze et al. (2017) & Quantitative & $\begin{array}{l}97 \text { late teenage gamers aged } 18- \\
39 \text { in Belgium }\end{array}$ & $\begin{array}{l}\text { Behavior of playing online games } \\
\text { with IGD criteria. The first is the } \\
\text { classic DSM- } 5 \text { approach ( } \geq 5 \\
\text { criteria required to support an ED } \\
\text { diagnosis). The second consists of } \\
\text { using latent class analysis (LCA) } \\
\text { for ED criteria to differentiate }\end{array}$ & $\begin{array}{l}\text { Comparisons using both approaches (DSM- } 5 \text { and LCA) failed to } \\
\text { identify significant differences in all constructs except for variables } \\
\text { related to actual or problematic game behavior } \\
\text { The validity of the ED criteria is questionable, largely concerning } \\
\text { their relevance in differentiating high involvement from pathological } \\
\text { involvement in video games video }\end{array}$ \\
\hline
\end{tabular}

Goh et al. (2019) Cross-Sectional 165 participants in the UK.

$\begin{array}{lll}\begin{array}{l}\text { Throuvala et al. } \\ \text { (2019) }\end{array} & \text { Quantitative } & \begin{array}{l}225 \text { young adults are members of } \\ \text { the UK's online gaming community }\end{array} \\ \text { Hui et al. (2019) } & \text { Quantitative } & \begin{array}{l}200 \text { young Chinese adults aged } \\ 18-24 \text { years (mean age }= \\ 19.48 \text { years) }\end{array} \\ & & \begin{array}{l}402 \text { students aged } 17 \text { to } 25 \text { in } \\ \text { Turkey }\end{array}\end{array}$

Buiza-Aguado et al. observationa

(2018) transverse study

Wölfling et al. (2019) A multicenter trial 708 students age 15.6 - 2.7 years were included. Malaga- South of Spain

143 men were randomized to $\mathrm{n}=72$ ) or the waiting list control subgroups of gamers amount of time spent playing DOTA 2 (popular MOBA) and psychological well-being

Results show a significant correlation with higher levels of playtime associated with poorer psychological well-being. The "runaway" motivation partly mediates this relationship. Self-esteem found to moderate the negative impact of "escape" games on psychological well-being

Parental acceptance-denial theory The results showed that parental refusal was associated with and Internet gaming disorder and the occurrence of ED, only through a CSE-mediated effect (core Mediation and moderation of CSE self-evaluations) Impact of satisfaction and dissatisfaction on autonomy, competence, and relatedness in explaining Internet gaming disorder

Student internet addiction in relation to parental attachment and socio-demography

The results showed that relatedness dissatisfaction positively predicted ED symptoms after controlling for satisfaction and dissatisfaction with other needs. Also, progression was found to be negatively

One-way ANOVA results show that students whose fathers have a low level of education are more likely to have higher internet addiction scores than students whose fathers have a high level of predicted by the ED education. The results of Pearson's product-moment correlation coefficient showed that students' internet addiction scores were negatively correlated with age, mean grades, maternal care, maternal overprotection, paternal overprotection, and paternal overprotection. However, the results of the stepwise regression analysis showed that the most important predictors of internet addiction score were maternal overprotection and paternal overprotection Multivariate analysis showed that IGD+ scores were significantly group (WLC) $(\mathrm{n}=71)$. The main inclusion criteria were male gender and internet addiction as the main diagnosis in Germany and Austria

Internet gaming addiction (ER), health, psychosocial, gender, type of game

manual cognitive-behavioral therapy (CBT), short-term treatment for internet and computer game addiction (STICA), individuals who are addicted to the internet and computer games associated with poorer health and psychosocial adjustment $(p<0.001)$ and $H G)$ were not significantly associated $(p>0.01)$

Based on the theoretical model of IA, published and successfully pretested short-term CBT $($ STICA19,20) was performed at 4 different sites. We included a male sample age, 26 years; range, $17-52$ years) with addictive online and offline games or IA. This behavior addresses domains outside the Gaming Disorders Category, which will also be provided by the forthcoming International Classification of Diseases, $11^{\text {th }}$ Revision; nevertheless, it shares an understanding of behavioral disorders. A total of $52.4 \%$ of the patients had a comorbid mental disorder (mainly mild to moderate depression), and $14.7 \%$ received a stable psychotropic drug regimen serious psychological and medical conditions triggers a person's psychiatric condition, namely eating disorders [49]. According to research by FernándezVilla et al., 2015 [24] found that a significant relationship between several health problems (migraine, back pain, overweight or obesity, and insufficient rest), psychological aspects (risk of eating disorders, risk of mental disorders, and depression), family problems and discrimination, without any association with substance use (alcohol, marijuana, or tobacco) was found. For some players, however, excessive use fosters dependence which leads to negative psychosocial and health consequences. Research by Lin et al., 2014 on adolescents in Taiwan showed that adolescents with internet addiction were more likely to have suicidal ideation and attempts. Given that IA is associated with depression, poor family support, and low self-esteem, these factors increase the risk

Table 3: The impact of online game addiction on adolescent mental health

\begin{tabular}{lllll}
\hline Author (year) & Country & Adjusted odd ratio & $95 \% \mathrm{Cl}$ & $\mathrm{p}$-value \\
\hline Aguado et al. (2018) & Spanish & 1.66 & $0.54-5.10$ & 0.238 \\
Borges et al. (2019) & Mexico & 1.90 & $1.40-2.58$ & 0.050 \\
Han et al. (2020) & Korea & 1.52 & $1.03-2.24$ & 0.001 \\
Kawabe et al. (2016) & Japan & 1.42 & $0.95-2.12$ & 0.050 \\
Kojima et al. (2018) & Japan & 1.81 & $1.11-2.95$ & 0.010 \\
Lin et al. (2014) & Taiwan & 1.21 & $1.05-1.39$ & 0.002 \\
Otsuka et al. (2019) & Japan & 2.39 & $1.36-4.20$ & $<0.001$ \\
\hline
\end{tabular}

of suicide. Seeing that the emergency department is equated with addiction diseases such as narcotics addiction, perhaps the same thing applied to recovery can also be done for IA, especially online games, as it is important to have family support. This is under the results of a literature study by Devy Mulia Sari et al., 2021 on drug addicts. The existence of a good family role makes the recovery process more effective because a drug abuser will feel motivated towards the support provided [50].

Mental health is currently a problem faced by adolescent, especially during the COVID-19 pandemic. The use of social media by adolescent has also increased due to the coronavirus pandemic. This situation risks an increased risk of a decline in adolescent mental health due to posting self-presentations through social media such as Instagram. Tateno in his research found that the trend of men preferring games in their internet usage while women use the internet mainly for social networking via smartphones, and the average SAS-SV score (the SAS-Short Version) higher in women, this is in line with the review Ferina Agustia Yuarta, Ira Nirmala, 2021 which shows the findings that social media users are mostly women as much as $51 \%$ while for men, 49\% [51]. 


\begin{tabular}{|c|c|c|c|c|c|c|c|}
\hline Study or Subgroup & log[Odds Ratio] & SE & Weight & $\begin{array}{c}\text { Odds Ratio } \\
\text { IV, Random, } 95 \% \mathrm{Cl}\end{array}$ & $\begin{array}{r}\text { Odds F } \\
\text { IV, Randon }\end{array}$ & $\begin{array}{l}\text { Ratio } \\
\mathrm{m}, 95 \% \mathrm{Cl}\end{array}$ & \\
\hline Aguado 2018 & 0.5068 & 0.573 & $3.1 \%$ & $1.66[0.54,5.10]$ & & & \\
\hline Borges 2020 & 0.6419 & 0.1558 & $18.8 \%$ & $1.90[1.40,2.58]$ & & $\rightarrow-$ & \\
\hline Han 2020 & 0.4187 & 0.1986 & $15.0 \%$ & $1.52[1.03,2.24]$ & & - & \\
\hline Kawabe 2016 & 0.3507 & 0.2051 & $14.5 \%$ & $1.42[0.95,2.12]$ & & 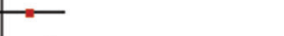 & \\
\hline Kojima 2018 & 0.5933 & 0.2495 & $11.5 \%$ & $1.81[1.11,2.95]$ & & - & \\
\hline Lin 2014 & 0.1906 & 0.0724 & $27.5 \%$ & $1.21[1.05,1.39]$ & & $=$ & \\
\hline Otsuka 2019 & 0.8713 & 0.2877 & $9.5 \%$ & $2.39[1.36,4.20]$ & & & \\
\hline Total $(95 \% \mathrm{Cl})$ & & & $100.0 \%$ & $1.57[1.28,1.94]$ & & 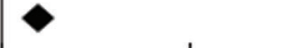 & \\
\hline \multicolumn{5}{|c|}{$\begin{array}{l}\text { Heterogeneity: } \mathrm{Tau}^{2}=0.04 ; \mathrm{Ch}^{2}=12.67, \mathrm{df}=6(\mathrm{P}=0.05) ; \mathrm{I}^{2}=53 \% \\
\text { Test for overall effect: } Z=4.27(P<0.0001)\end{array}$} & $0.01 \quad 0.1 \quad 1$ & $\begin{array}{c}10 \\
\text { Online Game Addiction }\end{array}$ & 100 \\
\hline
\end{tabular}

Figure 3: Forest plot the impact of online game addiction on adolescent mental health

To prevent the emergence of problematic use of technology and reduce harm, a multi-stakeholder approaches such as researchers, doctors, regulators, government agencies, community organizations, and industry is used. There is a need for health promotion about the dangers of online game addiction in adolescents as an intervention measure. However, this is sometimes inconsistent between several stakeholders. This is following the qualitative research conducted by Mutmainah et al., 2020, which showed the results thatnot all stakeholders have strong strength, positive attitude, and active interest in developing adolescent health promotion media. Only two stakeholders (health sector and NGO) have a "savior" category because these stakeholders have health programs. Many stakeholders should be involved, but there is still overlap in reality, and some stakeholders even say that it is not important youth health promotion media. Stakeholder providers tend to have weak power and passive interest because media youth health promotion is usually given directly from stakeholder decision makers [51]. The most possible thing to do health promotion about the dangers of online game addiction is with confidence in the sustainable supporting factors recognizing the important role of stakeholders to advocate the re-activation of peer educator programs for high school students as a clear sign of support [53].

Internet technology has dramatically changed our daily lives and also changed the way we communicate. As social media apps become more popular, users are more closely connected to the internet and time spent with other people in the real world decreases. Boys often isolate themselves from the social community to engage in games online while women use the internet to avoid being ostracized addicted to the Internet and Smartphones for their online communication. Mental health providers should be aware of the seriousness of IA. Wise use of the internet is the only relevant prevention at this time to avoid the IGD.

Figure 3 shows the results of the forest plot of the impact of online game addiction on adolescent mental health. The results of the forest plot show that adolescents with online game addiction can increase mental health disorders by 1.57 times compared to adolescents who do not have online game addiction. The results were statistically significant $(p \leq 0.001)$. Heterogeneity $(12)=53 \%$ indicates the spread of heterogeneous data (random effect model).

Figure 4 shows no publication bias indicated by the symmetrical shape of the graph, there are three plots on the right and three plots on the left. The left plot has a standard error of 0.2 to moderate. The plot on the right has a standard error between 0.6 and 0.2. The absence of bias can also be seen from the balanced distance between studies in both the right and left plots.

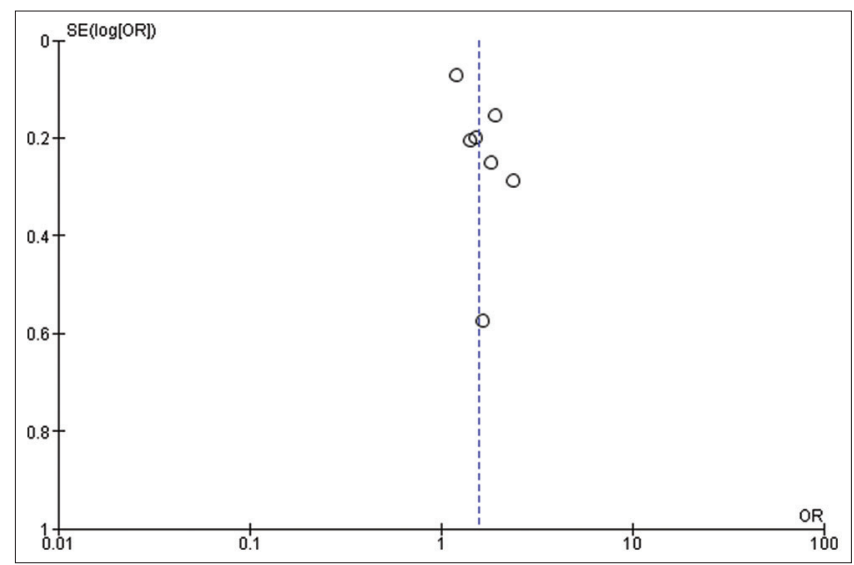

Figure 4: Funnel plot impact of online game addiction on adolescent mental health

\section{Conclusion}

A systematic study conducted by researchers focused on online game addiction and adolescent mental health. Articles based on specific inclusion criteria showed a significant relationship between excessive online gaming behavior (addiction) and adolescent mental health. Future researchers are expected to use this systematic review study as a reference when trying to assess the impact of excessive online gaming behavior on adolescent mental health and relevant and clinically tested prevention and treatment. 


\section{Author's Contribution}

Eni Purwaningsih is the main writer who selects topics, searches and collects research data and analyze research data; Ira Nirmala played a role in reviewing articles.

\section{References}

1. Kuss D, Gainsbury S. Debate: Behavioural addictions and technology use - risk and policy recommendations for problematic online gambling and gaming. Child Adolesc Ment Health. 2021;26(1):76-7. https://doi.org/10.1111/camh.12449 PMid:33426713

2. Yao YW, Chen PR, Chen C, Wang LJ, Zhang JT, Xue G, et al. Failure to utilize feedback causes decision-making deficits among excessive Internet gamers. Psychiatry Res. 2014;219(3):583-8. https://doi.org/10.1016/j.psychres.2014.06.033 PMid:25024056

3. De Pasquale C, Sciacca F, Martinelli V, Chiappedi M, Dinaro C Hichy Z. Relationship of internet gaming disorder with psychopathology and social adaptation in Italian young adults. Int J Environ Res Public Health. 2020;17:8201. https://doi. org/10.21203/rs.3.rs-15488/v1

PMid:33172015

4. Beranuy M, Machimbarrena JM, Vega-Osés MA, Carbonell $X$, Griffiths MD, Pontes HM, et al. Spanish validation of the internet gaming disorder scale-short form (IGDS9-SF): Prevalence and relationship with online gambling and quality of life. Int J Environ Res Public Health. 2020;17(5):1562. https://doi.org/10.3390/ ijerph17051562

PMid:32121280

5. Choi $\mathrm{C}$, Hums MA, Bum $\mathrm{CH}$. Impact of the family environment on juvenile mental health: eSports online game addiction and delinquency. Int J Environ Res Public Health. 2018;15:2850. https://doi.org/10.3390/ijerph15122850

PMid:30551658

6. Anand N, Thomas CC, Jain PA, Bhat A, Thomas CC Prathyusha PV, et al. Internet use behaviors, internet addiction and psychological distress among medical college students: A multi centre study from South India. Asian J Psychiatr. 2018;37:71-7. https://doi.org/10.1016/j.ajp.2018.07.020 PMid:30145540

7. Stavropoulos V, Baynes KL, O'Farrel DL, Gomez R, Mueller A, Yucel $\mathrm{M}$, et al. Inattention and disordered gaming: Does culture matter? Psychiatr Q. 2020;91:333-48. https://doi.org/10.1007/ s11126-019-09702-8

PMid:31900821

8. Nie $\mathrm{NH}$, Hillygus DS. The impact of internet use on sociability: Time-diary findings. IT Soc. 2002;1:1-20.

9. Tateno M, Teo AR, Ukai W, Kanazawa J, Katsuki R, Kubo H, et al. Internet addiction, smartphone addiction, and hikikomori trait in Japanese young adult: Social isolation and social network. Front Psychiatry. 2019;10:455. https://doi.org/10.3389/ fpsyt.2019.00455 PMid:31354537

10. Wartberg L, Kammerl R. Empirical relationships between problematic alcohol use and a problematic use of video games, social media and the internet and their associations to mental health in adolescence. Int J Environ Res Public Health. 2020;17(17):6098. https://doi.org/10.3390/ijerph17176098 PMid:32825700

11. Jo SJ, Jeong H, Son HJ, Lee HK, Lee SY, Kweon YS, et al. Diagnostic usefulness of an ultra-brief screener to identify risk of online gaming disorder for children and adolescents. Psychiatry Investig. 2020;17(8):762-8. https://doi.org/10.30773/ pi.2019.0279

PMid:32777921

12. Bhisma M. Prinsip dan Metode Riset Epidemiologi. $5^{\text {th }}$ ed Surakarta: Masters Program in Public Health; 2018.

13. Widayati $P$, Rahardjo SS, Widyaningsih V. Meta-analysis on the effect of zinc on reducing diarrhea episode in toddlers. Indones J Med. 2019;4:183-91. https://doi.org/10.26911/ theijmed.2019.04.02.12

14. Anulus A, Murt B, Prasetya H. Risk factors of HIV among male military personnels: A meta analysis. J Heal Promot Behav. 2019;4:178-88. https://doi.org/10.26911/thejhpb.2019.04.03.03

15. Throuvala MA, Janikian $M$, Griffiths MD, Rennoldson $M$, Kuss DJ. The role of family and personality traits in Internet gaming disorder: A mediation model combining cognitive and attachment perspectives. J Behav Addict. 2019;8(1):48-62. https://doi.org/10.1556/2006.8.2019.05 PMid:30739463

16. Lai FT, Kwan JL. Socioeconomic influence on adolescent problematic internet use through school-related psychosocial factors and pattern of Internet use. Comput Human Behav. 2017;68:121-36. https://doi.org/10.1016/j.chb.2016.11.021

17. Xin M, Xing J, Pengfei W, Houru L, Mengcheng W, Hong Z Online activities, prevalence of Internet addiction and risk factors related to family and school among adolescents in China. Addict Behav Reports. 2018;7:14-8. https://doi.org/10.1016/j. abrep.2017.10.003 PMid:29450251

18. Chamarro A, Oberst $\mathrm{U}$, Cladellas $\mathrm{R}$, Fuster $\mathrm{H}$. Effect of the frustration of psychological needs on addictive behaviors in mobile videogamers the mediating role of use expectancies and time spent gaming. Int J Environ Res Public Health. 2020;17(17):6429. https://doi.org/10.3390/ijerph17176429 PMid:32899364

19. Phan O, Prieur C, Bonnaire C, Obradovic I. Internet gaming disorder: Exploring its impact on satisfaction in life in PELLEAS adolescent sample. Int J Environ Res Public Health. 2020;17(1):3. https://doi.org/10.3390/ijerph17010003 PMid:31861283

20. Király O, Urbán R, Griffiths MD, Ágoston C, Nagygyörgy $K$ Kökönyei $\mathrm{G}$, et al. The mediating effect of gaming motivation between psychiatric symptoms and problematic online gaming: An online survey. J Med Internet Res. 2015;17(4):e88. https:// doi.org/10.2196/jmir.3515 PMid:25855558

21. Kindt S, Szász-Janocha C, Rehbein F, Lindenberg K. Schoolrelated risk factors of internet use disorders. Int $\mathrm{J}$ Environ Res Public Health. 2019;16:4938. https://doi.org/10.3390/ ijerph16244938

22. González-Bueso V, Santamaría JJ, Oliveras I, Fernández D, Montero $\mathrm{E}, \mathrm{Baño} \mathrm{M}$, et al. Internet gaming disorder clustering based on personality traits in adolescents, and its relation with comorbid psychological symptoms. Int J Environ Res Public Health. 2020;17(5):1516. https://doi.org/10.3390/ ijerph17051516

PMid:32111070

23. Fernández-Villa $T$, Ojeda JA, Gómez AA, Carral JM, Delgado-Rodríguez M, García-Martín $\mathrm{M}$, et al. Problematic internet use in university students: Associated factors and 
differences of gender. Adicciones. 2015;27(4):265-75. https:// doi.org/10.20882/adicciones.751

PMid:26706809

24. Sioni SR, Burleson MH, Bekerian DA. Internet gaming disorder: Social phobia and identifying with your virtual self. Comput Human Behav. 2017;71:11-5. https://doi.org/10.1016/j. chb.2017.01.044

25. Phan O, Prieur C, Bonnaire C, Obradovic I. Internet gaming disorder: Exploring its impact on satisfaction in life in PELLEAS adolescent sample. Int J Environ Res Public Health. 2020;17(1):3. https://doi.org/10.3390/ijerph17010003 PMid:31861283

26. Lin CY, Potenza MN, Broström A, Pakpour AH. Internet gaming disorder, psychological distress, and insomnia in adolescent students and their siblings: An actor-partner interdependence model approach. Addict Behav Reports. 2021;13:100332. https://doi.org/10.1016/j.abrep.2020.100332 PMid:33437860

27. Andreassen CS, Billieux J, Griffiths MD, Kuss DJ, Demetrovics Z, Mazzoni $\mathrm{E}$, et al. The relationship between addictive use of social media and video games and symptoms of psychiatric disorders: A large-scale cross-sectional study. Psychol Addict Behav. 2016;30(2):252-62. https://doi.org/10.1037/adb0000160 PMid:26999354

28. Männikkö N, Billieux J, Kääriäinen M. Problematic digital gaming behavior and its relation to the psychological, social and physical health of Finnish adolescents and young adults. J Behav Addict. 2015;4(4):281-8. https://doi.org/10.1556/2006.4.2015.040 PMid:26690623

29. Han H, Jeong H, Jo SJ, Son HJ, Yim HW. Relationship between the experience of online game genre and high risk of Internet gaming disorder in Korean adolescents. Epidemiol Health. 2020;42:e2020016. https://doi.org/10.4178/epih.e2020016 PMid:32272007

30. Alshehri AG, Mohamed AM. The relationship between electronic gaming and health, social relationships, and physical activity among males in Saudi Arabia. Am J Mens Health. 2019;13(4):1557988319873512. https://doi. org/10.1177/1557988319873512

PMid:31462143

31. Deleuze J, Nuyens F, Rochat L, Rothen S, Maurage P, Billieux J. Established risk factors for addiction fail to discriminate between healthy gamers and gamers endorsing DSM- 5 Internet gaming disorder. J Behav Addict. 2017;6(4):516-24. https://doi. org/10.1556/2006.6.2017.074

PMid:29130328

32. Jeong H, Yim HW, Lee SY, Lee HK, Potenza MN, Kwon JH, et al. Discordance between self-report and clinical diagnosis of Internet gaming disorder in adolescents. Sci Rep. 2018;8(1):10084. https://doi.org/10.1038/s41598-018-28478-8 PMid:29973627

33. Vollmer C, Randler C, Horzum MB, Ayas T. Computer game addiction in adolescents and its relationship to chronotype and personality. SAGE Open. 2014;4:2158244013518054. https:// doi.org/10.1177/2158244013518054

34. Goh C, Jones C, Copello A. A further test of the impact of online gaming on psychological wellbeing and the role of play motivations and problematic use. Psychiatr Q. 2019;90(4):747-60. https:// doi.org/10.1007/s11126-019-09656-x

PMid:31385123

35. Sun $Y$, Sun J, Zhou $Y$, Ding W, Chen X, Zhuang Z, et al. Assessment of in vivo microstructure alterations in gray matter using DKI in internet gaming addiction. Behav Brain Funct. 2014;10:37. https://doi.org/10.1186/1744-9081-10-37

PMid:25344114
36. Chou WJ, Liu TL, Yang P, Yen CF, Hu HF. Multi-dimensional correlates of Internet addiction symptoms in adolescents with attention-deficit/hyperactivity disorder. Psychiatry Res. 2015;225(1-2):122-8. https://doi.org/10.1016/j. psychres.2014.11.003 PMid:25466226

37. Lee HJ, Tran DD, Morrell HE. Smoking, ADHD, and problematic video game use: A structural modeling approach. Cyberpsychol Behav Soc Netw. 2018;21(5):281-6. https://doi.org/10.1089/ cyber.2017.0429 PMid:29652524

38. Jia J, Tong W, Zhang J, Liu F, Fang X. Trajectory of problematic internet use across the college years: The role of peer internet overuse behavior and peer attitude toward internet overuse. J Adolesc. 2021;86:64-76. https://doi.org/10.1016/j. adolescence.2020.12.006

PMid:33360119

39. Hui BP, Wu AM, Siu NY, Chung ML, Pun N. The effects of need satisfaction and dissatisfaction on flourishing among young Chinese gamers: The mediating role of internet gaming disorder. Int J Environ Res Public Health. 2019;16(22):4367. https://doi. org/10.3390/ijerph16224367

PMid:31717399

40. Kumcağız H. Examination of Turkish university students' internet addiction in relation to their parental attachment styles and sociodemographics. SAGE Open. 2019;9:2158244019845946. https://doi.org/10.1177/2158244019845946

41. Lin $\mathrm{IH}$, Ko $\mathrm{CH}$, Chang YP, Liu TL, Wang PW, Lin HC, et al. The association between suicidality and Internet addiction and activities in Taiwanese adolescents. Compr Psychiatry. 2014;55(3):504-10. https://doi.org/10.1016/j. comppsych.2013.11.012 PMid:24457034

42. Buiza-Aguado C, Alonso-Canovas A, Conde-Mateos C, BuizaNavarrete JJ, Gentile D. Problematic video gaming in a young Spanish population: Association with psychosocial health. Cyberpsychol Behav Soc Netw. 2018;21(6):388-94. https://doi. org/10.1089/cyber.2017.0599

PMid:29792521

43. Wölfling $\mathrm{K}$, Müller $\mathrm{KW}$, Dreier $\mathrm{M}$, Ruckes $\mathrm{C}$, Deuster $\mathrm{O}$, Batra $A$, et al. Efficacy of short-term treatment of internet and computer game addiction: A randomized clinical trial. JAMA Psychiatry. 2019;76:1018-25. https://doi.org/10.1001/ jamapsychiatry.2019.1676

PMid:31290948

44. Chen KH, Oliffe JL, Kelly MT. Internet gaming disorder: An emergent health issue for men. Am J Mens Health. 2018;12(4):1151-9. https://doi.org/10.1177/1557988318766950 PMid:29606034

45. Rodda S, Vacaru MA, Knaebe B, Hodgins D, Rodda SN, Booth $\mathrm{N}$, et al. Behaviour Change Strategies for Internet, Pornography and Gaming Addiction: A Taxonomy and Content Analysis of Professional and Consumer Websites the Context of Gambling Treatment: Towards Creating an Online Service to Reduce Problem Gambling View Project Gambling and Eating Pathology View Project; 2018. https://doi.org/10.1016/j. chb.2018.03.021

46. Jamir L, Duggal M, Nehra R, Singh P, Grover S. Epidemiology of technology addiction among school students in rural India. Asian J Psychiatr. 2019;40:30-8. https://doi.org/10.1016/j. ajp.2019.01.009 PMid:30716701

47. Lin M, Kim Y. The reliability and validity of the 18-item long form and two short forms of the Problematic Internet Use Questionnaire in three Japanese samples. Addict Behav. 2020;101:105961. https://doi.org/10.1016/j.addbeh.2019.04.019 
PMid:31072647

48. Lopez-Fernandez O, Kuss DJ. Preventing harmful internet use-related addiction problems in Europe: A literature review and policy options. Int J Environ Res Public Health. 2020;17(11):3797. https://doi.org/10.3390/ijerph17113797 PMid:32471093

49. Ammar EN, Nurmala I. Analisis faktor sosio-kultural terhadap dimensi body image pada Remaja. J Heal Sci Prev. 2020;4:23-31. https://doi.org/10.29080/jhsp.v4i1.255

50. Sari DM, Fatah MZ, Nurmala N. Peran keluarga dalam membantu proses pemulihan penyalahguna narkoba family role to the recovery process of drug abuses. Indones $\mathrm{J}$ Health
Promot Health Educ. 2021;9:59-68.

51. Yuarta FA, Nurmala N. Improving mental health of adolescents through self-presentation. Indian J Forensic Med Toxicol. 2020;14:14722.

52. Muthmainnah, Nurmala I, Siswantara $P$, Hargono $R$, Harris N, Devi YP, et al. Power-attitude-interest of stakeholoders in developing adolescent health promotion media. Int J Innov Creat Chang. 2020;11:287-99.

53. Nurmala I, Pertiwi ED, Muthmainnah M, Rachmayanti RD, Devi YP, Harris N, et al. Peer-to-peer education to prevent drug use: A qualitative analysis of the perspectives of student peer educators from Surabaya, Indonesia. Heal Promot J Austr. 2020;2020:1-6. https://doi.org/10.1002/hpja.400

Author Queries???

AQ6: Kindly cite tables 2 and 3 in text part

AQ7: Kindly cite figure 1 in text part 